\title{
Evaluation of TEGDMA leaching from four resin cements by HPLC
}

Subutay Han Altintas

Aslihan Usumez ${ }^{2}$

\section{ABSTRACT}

Objective: The aim of this study was to evaluate the elution of TEGDMA from dual cured resin cements, used for bonding of ceramic restoration by high performance liquid chromatography (HPLC).

Methods: Forty freshly extracted caries and restoration free molar teeth used in this study. Standardized Class I preparations were prepared in all teeth. Ceramic inlays were cemented with one of the dual cured resin cements (Variolink II, Rely X ARC, Rely X Unicem and Resilute). After cementation, specimens were stored in $75 \%$ ethanol solution. HPLC was used to analyze the amounts of TEGDMA in different time intervals. Two-way ANOVA and Tukey HSD tests were used to evaluate the results $(P<.05)$.

Results: The amount of TEGDMA eluted from Resilute was the highest and the amount of TEGDMA eluted from Rely $X$ Unicem was the lowest $(P<.05)$. The total amount of monomers was the highest after 21 days $(P<.05)$.

Conclusion: In the case of resin cements, elution of TEGDMA was the highest in Resilute and lowest in Rely X Unicem. The amount of TEGDMA eluted from resin cements was influenced by the time. (Eur J Dent 2012;6:255-262)

Key words: Residual Monomer; TEGDMA; resin cements; HPLC; ceramic; inlay; ethanol

\section{INTRODUCTION}

In recent years, many luting agents and resin cements have been introduced to clinicians with the claim of clinically better performance than existing materials due to improved characteristics. The luting of indirect restoratives to abutments is

1 Department of Prosthodontics, Faculty of Dentistry, Karadeniz Technical University, Trabzon, TURKIYE

2 Department of Prosthodontics, Faculty of Dentistry, Bezmialem Vakif University, Istanbul, TURKIYE

- Corresponding author: Dr. Subutay Han Altintas Karadeniz Technical University, Faculty of Dentistry, Department of Prostodontics 61080 Campus/Trabzon, TURKIYE Tel: +905336414699

Fax: +904623253017

Email: subutayhandayahoo.com critical in achieving proper performance of indirect restorations.'

Luting materials must undergo a chemical reaction to harden. This reaction can be initiated in one of three main manners: (1) mixing two or more different components of the material, which is improperly termed chemical polymerization; (2) activating photosensitive molecules of the material in visible light polymerization; or (3) a combination of both methods, called dual polymerization. It is relevant to clinicians that the type of polymerization greatly influences three important aspects of the luting procedure: its control, its pace, and access. ${ }^{2}$

Dimethacrylate monomers are widely used in dentistry and form an essential ingredient in dentin bonding agents, restorative dental composites, 
luting agents and fissure sealants. ${ }^{3,4}$ The selection of the monomer strongly influences the reactivity, viscosity, and polymerization shrinkage of the monomer, as well as the mechanical properties, water uptake, and swelling by water of the resin. ${ }^{5}$ The resin matrix includes one or more so-called 'heavy' monomer systems le.g. Bisphenol A glycidylmethacrylate, Bis-GMA, urethanedimethacrylate, UDMAl and 'light' co-monomer systems le.g. triethyleneglycoldimethacrylate, TEGDMA, hydroxyethylmethacrylate, HEMAl to reduce the viscosity of monomers and to enhance bonding strength to dentine. ${ }^{6}$

Acrylates, mainly methacrylates, were found to cause cytotoxic effects. Evaluation of the cytotoxicity of 39 acrylates and methacrylates that were used in dental resin materials showed a relationship between their structure and the degree of cytotoxicity. ${ }^{1}$ The mechanism of cytotoxicity induced by TEGDMA in human fibroblasts has been recently studied. ${ }^{7}$ TEGDMA was recently found to be moderately mutagenic in V79 cells in subtoxic concentrations, ${ }^{8}$ and might promote the proliferation of the important cariogenic microorganisms Lactobacillus acidophilus and Streptococcus sobrinus. ${ }^{9}$

The determination of the quality and quantity of the residual monomers is usually performed by using high-performance liquid chromatography (HPLC), ${ }^{10}$ as it is a very powerful and commonly used separation method. It is preferred to gas chromatography because it provides a greater level of control over the separation process, in this case because the monomers are soluble in the mobile phase. ${ }^{11}$

The elution process of monomers released from dental resin composites has been widely studied in the literature. ${ }^{12-19}$ The main concerns are the amount of leachable monomers and duration of time needed for the complete elution, but there is little information about the roles of the size and chemical characteristics of the monomers. In addition, there is contradictory information about the time needed for the complete elution of the extractable amount of unreacted monomers. ${ }^{20}$ Some studies have indicated that the elution is completed in 1 to 7 days, while other studies have found that it lasts for a longer period of time. ${ }^{17,19}$ There is interest in identifying resin cements as a potential source of unreacted monomers in oral and other environmental tissues.
The aim of this study was to evaluate with HPLC in vitro elution of TEGDMA from resin cements IVariolink II, Ivoclar Vivadent AG, Schaan, Liechtenstein; Rely X Unicem, 3M ESPE, Seefeld, Germany; Rely X ARC, 3M ESPE, Seefeld, Germany; Resilute, Pulpdent Co. Watertown, USA) with dual polymerization mechanisms used for bonding of ceramic inlay restorations. The first research hypothesis was that after polymerization of resin cements there would be elution of residual monomers in ethanol/water solution. The second research hypothesis was that the number of residual monomers would increase with time.

\section{MATERIALS AND METHODS}

Forty freshly extracted caries and restoration free molar teeth were used in this study. All teeth were embedded in acrylic molds. Then standardized box-shaped Class I inlay preparations were prepared with 5-degree conical burs (no. S6845KR, Komet Dental, Gmungen, Austrial and 5-degree micro fine conical diamond burs (no. $8845 \mathrm{KR}$, Komet Dental, Gmungen, Austria.) in a high-speed hand piece mounted on standard cavity machine (Nova mcm, Nova Ltd, Konya, Turkiye). Each inlay preparation was, $6 \mathrm{~mm}$ in length, $3 \mathrm{~mm}$ in width, and $2 \mathrm{~mm}$ in depth and had 5 -degree convergence of the walls.

Impressions were made of all teeth preparations with polyether impression material (3M ESPE AG, Dental Products, Seefeld, Germanyl and poured in a vacuum mixed polyurethane die material (Alpha Die MF, Schültz-Dental GmbH, Rosbach, Germanyl according to the manufacturer's instructions. To fabricate IPS Empress Esthetic (Ivoclar, Vivadent, Shcaan, Liechtenstein) inlays, polyurethane dies were painted with 2 coats of light polymerized die spacer (Renfert USA inc,Illinois, USAl to produce $40 \mu \mathrm{m}$ space on lateral walls for resin cement. Inlay restorations were waxed (Yeti Dental Produkte GmbH, Engen, Germany) and sprued. Ceramic inlays were pressed after investment. All procedures were performed with IPS Empress Esthetic materials and protocol. After divestment, ceramic inlays were finished with diamond burs (no. 863-11-016, Komet Dental,Gebr Brasseler, Germanyl and glazed. The adaptation of the inlay to the tooth cavity was evaluated by means of silicone replica technique. The replica specimens were sectioned bucco-lingually and 
mesio-distally and the inlays were investigated for occlusal and proximal marginal gap width under a light microscope (Axiotech Vario/100 HD, Zeiss, Jena, Germanyl at 200x magnification. Measurements of the marginal gap widths were performed one location and at three points at occlusal margins resulting in six measurements of occlusal location and totaling 6 measurements of each replica. At occlusal the marginal gap width was measured as the shortest distance between the edge of the inlay and the tooth structure. Mean value of gaps were obtained at $43.23 \pm 8.4 \mu \mathrm{m}$.

Before cementation acrylic blocks were fixed to the mounting plate of a slow-speed diamond saw sectioning machine (Isomet, Buehler Ltd., Lake Bluff, IL, USA). The roots were removed from the remaining crown approximately 1 to $2 \mathrm{~mm}$ below the cemento-enamel junction. Then the aperture of root sealed with amalgam (KerrAlloy, Kerr Dental, Orange, CA, USAl to prevent extra monomer leaching from pulp chamber.

The all ceramic inlays were treated with fluoridic acid (Ceramic Etchant, Ceramco, Burlington, $\mathrm{NJ}$ ) for 1 minute and neutralized (Ceramic Etchant Neutralizer, Ceramcol in accordance with the manufacturer's instructions. For luting samples with Vaiolink II resin cements, Silane (Monobond S, Ivoclar) was first applied with a brush to the ceramic inlays for 60 seconds, and then a bonding agent (Heliobond, Ivoclar) was applied. After the teeth were etched, primer (Syntac Primer, Ivoclar) was applied to the tooth surface for 15 seconds, adhesive (Syntac Adhesive, Ivoclar) for 10 seconds, and then a bonding agent (Heliobond, Ivoclar) with a brush. Resin cement, comprising a combination of $50 \%$ white base, and $50 \%$ catalyst was handmixed following the manufacturer's directions, and applied to both prepared teeth and the ceramic inlays. For Rely X Unicem, capsules of cements were mixed 15 s by Rotamix (3M ESPE, Seefeld, Germanyl and applied on surfaces of restorations and dentin cavity walls. For Rely X ARC, Silane (Ceramic Primer; 3M ESPE) was first applied with a brush to the ceramic inlays for $60 \mathrm{~s}$ and dried for $5 \mathrm{~s}$. The cavity walls was etched for $15 \mathrm{~s}$ with Scotchbond etchant (3M ESPE) and rinsed. After consecutive coats of $3 \mathrm{M}$ Single Bond adhesive was applied on the cavity wall and dry for $5 s$, cement was mixed 10s applied on surface of cavity walls and restorations. For Resilute, the adhesive sys- tem of Variolink II was used according to manufacturer's instruction with cement. Resilute Part 1 and Part 2 was mixed and applied on surface of cavity walls and restorations. The samples were weighted before and after cementation. The eluted mean amount of Variolink II, Rely X Unicem, Rely $X$ ARC, Resilute respectively were $22.9 \pm 3.2 \mathrm{mg}$, $23.58 \pm 4.8 \mathrm{mg}, 17.5 \pm 3.3 \mathrm{mg}, 17.1 \pm 4.1 \mathrm{mg}$.

The ceramic inlays were placed on the prepared teeth with light finger pressure. 21 Photopolymerization was performed with the light-polymerizing unit (Hilux Ultra Curing Unit, Benlioğlu Dental Inc., Ankara, Turkiye) at $550 \mathrm{~mW} / \mathrm{cm}^{2}$ (with a light tip to specimen distance of $0 \mathrm{~mm}$ ) for 40 seconds for occlusal, lingual, and buccal surfaces. After undergoing light polymerization, excessed cements were removed by using $15 \mu$ diamond bur 1852EF.314.014, Komet Dental, Gmungen, Austria) and cleaned with a rubber cup 19402204030, Komet Dental, Gmungen, Austrial on a slow-speed hand piece for $15 \mathrm{~s}$. The chemical composition is listed in Table 1.

All specimens were immersed immediately in light proof glass bottles containing $75 \%$ ethanol, $25 \%$ deionized water ${ }^{15,22}$ after polymerization of resin cements and stored at $37^{\circ} \mathrm{C}$. The extracts were taken off for every time interval without refreshing $(10$ minutes., 1 hour, 24 hours, 3 days, 7 days, 14 days, 21 days) from bottles which have immersed specimens. Residual monomer (TEGDMAl which eluted from resin cement in ethanol solution were analysed with HPLC.

\section{HPLC analysis}

The analysis of extracts from the resin cement as well as reference solutions of the monomers in water/acetonitrile (25:75) was carried out by HPLC (Agilent Technologies, USA) with the following conditions:

Column: steel column (Waters Corporation, Milford Massachusetts, USA),

$250 \mathrm{~mm}$ in length, $4.6 \mathrm{~mm}$ in diameter, and particle size of $5 \mu \mathrm{m}$.

Mobile phase: CH3CN 75\%/H2O 25\% (Acetonitrile)

Flow speed: $1 \mathrm{~mL} / \mathrm{min}$.

Detection: UV: $208 \mathrm{~nm}$ for TEGDMA

Injection: $10 \mu \mathrm{L}$ loop at constant room temperature

All measurements were performed 3 times 
for each of the extracts. Calibration curves were made relating eluted peak area to known concentrations of TEGDMA. The elution time for TEGDMA was $3.446 \mathrm{~min}$. The concentrations of the leaching monomers from resin matrix were calculated by using the coefficients obtained by a linear regression analysis of the results from the Standard series. Linear calibration equation for TEGDMA is shown in Table 2.

The data of eluted residual monomer from resin cement in time intervals were analysed by two way analysis of variance (ANOVA) (residual cements and time intervals) and Tukey HSD test. The data of residual monomers eluted in different time intervals were analyzed by one way ANOVA and Tukey HSD tests.

\section{RESULTS}

The two way ANOVA indicated that amount of residual monomer values vary according to the materials (TEGDMA) $(\mathrm{P}<.01)$ and time intervals (10 min, 1 hour, 24 hours, 72 hours, 7 days, 14 days, 21 days) $(P<$.01) (Table 3). Mean and standard deviations of groups are presented in Table 4.

While the amount of eluted TEGDMA from Resilute was significantly higher than other three cement, the amount of eluted TEGDMA from Rely $X$ Unicem was significantly lower than other ce- ments $(P<.01)$ and there were no statistically significant differences among Variolink II and Rely $X$ ARC ( $P=$.57)

In all resin cements investigated, the amount of TEGDMA in 10 minutes and 1 hour and 1 day were significantly lower than the amount in 21 days $(P<.01)$. There were no statistically significant differences among $3,7,14$ and 21 days $(P=.05$ ) (Table 4) (Figure 1).

\section{DISCUSSION}

In this study, the elution of TEGDMA from resin cements in ethanol/water solution over time is evaluated. The results obtained supported the first and second research hypotheses that after polymerization of resin cements, there would be elution of TEGDMA in ethanol/water solution over certain time intervals and that the amount of residual monomers would increase with time. This in vitro study measured the elution of TEGDMA from resin cements which is polymerized by a dual polymerization mechanism used for luting IPS Empress Esthetic ceramic restorations by HPLC. TEGDMA was eluted from the resin cements at all time interval.

The greater the extent of polymerization reactions, the fewer the residual monomers are available to be leached. It is known that degree of con-

Table 1. The chemical composition of resin cements.

\begin{tabular}{|c|c|c|}
\hline Resin cement & Name of manufacturer & Chemical composition \\
\hline Variolink II & $\begin{array}{l}\text { Ivoclar Vivadent AG, } \\
\text { Schaan/ Liechtenstein }\end{array}$ & $\begin{array}{l}\text { Syntac primer: maleic acid, TEGDMA, water, acetone } \\
\text { Syntac adhesive: maleic acid. TEGDMA, glutaraldehyde, water } \\
\text { Heliobond: Bis-GMA.TEGDMA } \\
\text { Paste A: Bis-GMA.urethane dimethacrylate, TEGDMA, inorganic filler, } \\
\text { ytterbium trifluoride, initiator, stabilizer } \\
\text { Paste B: Bis-GMA, UDMA, TEGDMA, inorganic filler, ytterbium trifluoride, } \\
\text { benzoyl peroxide, stabilizer }\end{array}$ \\
\hline Rely X Unicem & $\begin{array}{l}\text { 3M ESPE AG Dental } \\
\text { Products, Seefeld/ } \\
\text { Germany }\end{array}$ & $\begin{array}{l}\text { Methacrylated Phosphorıc Acid } \\
\text { Esters } \\
\text { Trıethylene Glycol Dımethacrylate } \\
\text { Substıtuted Dımethacrylate }\end{array}$ \\
\hline RelyX ARC & $\begin{array}{l}\text { 3M ESPE AG Dental } \\
\text { Products, Seefeld/ } \\
\text { Germany }\end{array}$ & $\begin{array}{l}\text { Ceramic primer: Ethyl Alcohol, Water } \\
\text { Scotchbond }{ }^{(T m)} \text { Phosphorıc etching gel: Water, } \\
\text { Phosphoric, Acid Synthetic Amorphous Silica } \\
\text { Paste A: Silane Treated Ceramic TEGDMA, BADGE Silane } \\
\text { Treated Silica Functionalised } \\
\text { Dimethacrylate Polymer } \\
\text { Paste B: Silane Treated Ceramic TEGDMA, BISGMA Silane, } \\
\text { Treated Sılıca Functıonalısed Dımethacrylate Polymer } \\
\text { Single bond: Ethyl Alcohol, Water, TEGDMA, Bis-GMA } \\
\text { Dimetakrilat polimerleri, HEMA } \\
\text { 2-hydroxy-1.3-dimethacryloxypropane Copolymer Of Acrylıc and Itaconıc Acids, UDMA }\end{array}$ \\
\hline Resilute & $\begin{array}{c}\text { Pulpdent Corporation } \\
\text { Watertown/ USA }\end{array}$ & $\begin{array}{l}\text { Syntac primer: maleic acid, TEGDMA, water, acetone } \\
\text { Syntac adhesive: maleic acid, TEGDMA, glutaraldehyde, water } \\
\text { Heliobond: Bis-GMA, TEGDMA Base + catalyst: Methacrylates }\end{array}$ \\
\hline
\end{tabular}


version (DC) of light polymerized resin materials is $55-80 \% .23,24$ The $D C$ of $C=C$ also depends on the type, duration and intensity of the light source and some properties of the resin system such as depth of the resin material. ${ }^{25-27}$ According to Rueggeberg and Craig, ${ }^{28}$ there is an inverse correlation between DC and percent of elution. Reduced irradiation increases solubility significantly. ${ }^{29}$ Increasing irradiation time from 30 s to 50 s results in a significant decrease in residual monomer contents and the quantities which are released into water. ${ }^{19}$ In the present study, the resin cements were polymerized according to the manufacturers

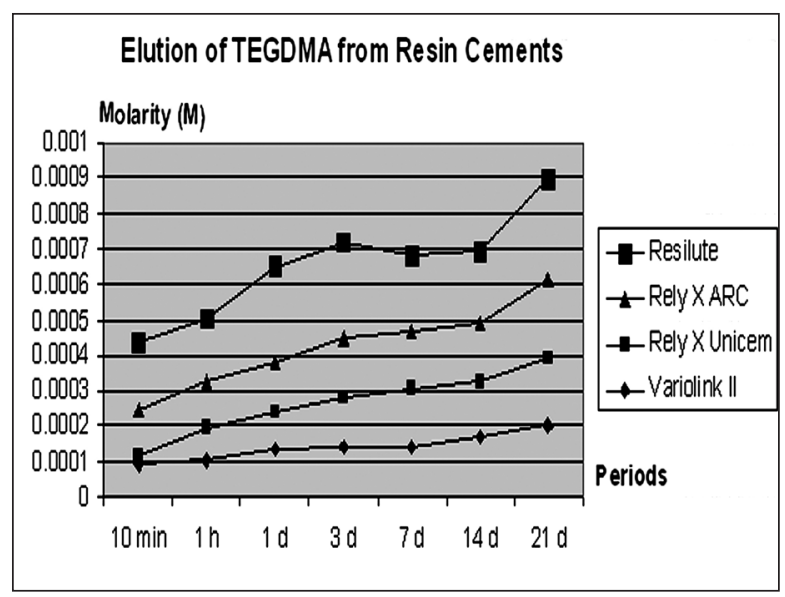

Figure 1. Cumulative monomer leaching values categorized according to resin cements and time intervals. Values are presented as Molarity (M).

Table 2. Linear calibration equations for TEGDMA. instructions with a halogen light source for 40 s. Several studies have been conducted to determine the influence of the type of solvent and duration upon the release of substances from resin materials. ${ }^{15,19}$ Various solvents such as distilled water, saliva, ethanol, methanol and acetonitrile have been used in studies for evaluating leaching of monomers. Cross-linked dimethacrylate resins are virtually insoluble but are capable of swelling in good solvents. ${ }^{18,27}$ Because degradation of resins in the oral cavity depends on salivary enzymatic reactions, acidic conditions and erosive factors caused by foods and drinks, ${ }^{30}$ organic solvents such as ethanol, methanol or mixtures of these solvents with water are especially preferred to simulate oral conditions. ${ }^{27}$ Organic solvents have the ability to penetrate and swell the polymer network, facilitating the liberation of unreacted and leachable monomers. As the solvent penetrates the matrix and expands the openings between polymer chains, oligomers diffuse out. ${ }^{27}$ Intraoral fluids represent solvents probably somewhere between the more aggressive organic solvents and water; the US FDA recommends a $75 \%$ ethanol-water solution as a food/oral-simulating liquid in order to be clinically relevant. ${ }^{23}$ Therefore, in the present study, $75 \%$ ethanol-25\% deionized water was used

\begin{tabular}{lccc}
\hline Monomer & $\lambda(\mathrm{nm})$ & $\mathrm{r}^{2}$ & Equation \\
\hline TEGDMA & 208 & 9.899 & $\mathrm{y}=7.8365 \mathrm{E}+05 \mathrm{x}+1.8544 \mathrm{E}+02$ \\
\hline
\end{tabular}

Table 3. Two way analysis of variance indicates the amount of residual monomer values vary according to the materials. SS: Sum of square, DF: Degree of freedom, MS: Mean square.

\begin{tabular}{lccccc}
\hline & SS & DF & MS & F & Sig. \\
\hline Material & $4.54 \mathrm{E}-07$ & 3 & $1.51 \mathrm{E}-07$ & .000 & 22,09 \\
Period & $2.58 \mathrm{E}-07$ & 6 & $4.30 \mathrm{E}-08$ & 6,27 & .000 \\
Material \& Period & $7.80 \mathrm{E}-08$ & 15 & $5.20 \mathrm{E}-09$ & 0,76 & .723 \\
\hline
\end{tabular}

${ }^{*}$ E indicates $10^{x}$

Table 4. TEGDMA concentrations eluted from the resin cements in 7 different time intervals.

\begin{tabular}{lcccc}
\hline Periods & Variolink II & Rely X Unicem & Rely X ARC & Resilute \\
\hline 10 min & $89.4 \pm 42.9 \mathrm{E}-6^{\mathrm{a}}$ & $26.8 \pm 13.7 \mathrm{E}-6^{\mathrm{A}}$ & $130.4 \pm 71.7 \mathrm{E}-6^{\mathrm{A}}$ & $188.32 \pm 55.4 \mathrm{E}-6^{\mathrm{a}}$ \\
\hline 1 hours & $101.5 \pm 65.2 \mathrm{E}-6^{\mathrm{ab}}$ & $93.7 \pm 60.1 \mathrm{E}-6^{\mathrm{AB}}$ & $132.2 \pm 90.8 \mathrm{E}-6^{\mathrm{A}}$ & $178.5 \pm 72.4 \mathrm{E}-6^{\mathrm{a}}$ \\
1 day & $133.8 \pm 44.7 \mathrm{E}-6^{\mathrm{ab}}$ & $105.9 \pm 73.4 \mathrm{E}-6^{\mathrm{AB}}$ & $138.3 \pm 71.6 \mathrm{E}-6^{\mathrm{A}}$ & $271.2 \pm 115 \mathrm{E}-6^{\mathrm{a}}$ \\
\hline 3 days & $139.0 \pm 37.8 \mathrm{E}-6^{\mathrm{ab}}$ & $146.1 \pm 58 \mathrm{E}-6^{\mathrm{AB}}$ & $160.2 \pm 79.0 \mathrm{E}-6^{\mathrm{A}}$ & $269.5 \pm 91.7 \mathrm{E}-6^{\mathrm{a}}$ \\
\hline 7 days & $142.5 \pm 60.1 \mathrm{E}-6^{\mathrm{ab}}$ & $161.9 \pm 104 \mathrm{E}-6^{\mathrm{AB}}$ & $161.3 \pm 75.5 \mathrm{E}-6^{\mathrm{A}}$ & $216.3 \pm 64 \mathrm{E}-6^{\mathrm{a}}$ \\
\hline 14 days & $173.6 \pm 68.2 \mathrm{E}-6^{\mathrm{b}}$ & $149.5 \pm 122 \mathrm{E}-6^{\mathrm{AB}}$ & $167.1 \pm 79 \mathrm{E}-6^{\mathrm{A}}$ & $205.7 \pm 104 \mathrm{E}-6^{\mathrm{a}}$ \\
\hline 21 days & $203.8 \pm 55.4 \mathrm{E}-6^{\mathrm{b}}$ & $190.2 \pm 130 \mathrm{E}-6^{\mathrm{B}}$ & $219.9 \pm 120 \mathrm{E}-6^{\mathrm{A}}$ & $282.6 \pm 133 \mathrm{E}-6^{\mathrm{a}}$ \\
\hline
\end{tabular}

${ }^{*}$ Groups with different type of letters are statistically significantly different.

The concentration values were calculated as M (Molarity). 
as an extraction medium to measure monomer release.

Adequate polymerization is crucial in obtaining optimal physical properties and clinical performance of resin composites. ${ }^{31}$ Ideally, a dental restorative resin might have all of its monomers converted to polymers during the polymerization reaction. Dual-cure materials are intended to be more effective in the early stages of polymerization because they contain both photoinitiators and components for a chemically activated reaction. Braga et al $^{32}$ investigated the early shear strength of porcelain-dentin bonding using dual-cure cements at 10,30, and 90 min and reported significant differences between 10 and 30 min. Krishnan et $\mathrm{al}^{33}$ reported that the solubility of visible lightcured dental composite was found to increase with time in their study on the effect of diluents on the properties of a visible light-cured dental composite at specific intervals of $1,7,14,21,28$, and 30 days. In addition, Kavara et $\mathrm{al}^{34}$ investigated the elution of residual monomers by HPLC analysis at time intervals of $1,3,6,12$, and 24 hours and 3,7 , and 14 days. To determine early and late elution of monomers from dual-cured resin cement, the time intervals of $10 \mathrm{~min}, 1$ hour, and 1, 3, 7, 14, and 21 days were determined.

Molecules of high molecular weight, base monomers such as Bis-GMA and UDMA, however, decompose in gas chromatographs and only the decomposition products of these are detectable. ${ }^{16}$ For this reason most studies on large monomers have been analysed by HPLC, ${ }^{10,13,16}$ which is preferred to gas chromatography because it provides a greater level of control over the separation process, in this case since the monomers are soluble in the mobile phase. ${ }^{11}$ HPLC analysis was used in this study to evaluate monomer release from resin cements because it is a very powerful and commonly used separation method.

The polymer network is composed of crosslinked molecules within which the unreacted monomers reside. As the solvent penetrates the matrix and expands the openings between polymer chains, monomers diffuse out. Although complete saturation of the composite with solvent requires weeks or months as a result of the slow nature of the diffusion of chemicals into the cross-linked resin matrix, elution appears to be completed within days because subsequent weight changes are so small as to be almost immeasurable. Therefore, although further leaching may occur with time, the majority of the elutable species are extracted from any exposed surface within a matter of hours. ${ }^{23} \mathrm{~A}$ study conducted by Lee et $\mathrm{al}^{14}$ concluded that the elution of monomers from dental resin composite specimens stored at $37^{\circ} \mathrm{C}$ for 7,14 , and 30 days increased as a function of time, and the quantity of monomers in 30 days storage was 5-7 times higher than what was produced after 7 days storage. This result is in accordance with the results of the current study, which concluded that the cumulative quantity of residual monomers was the highest after 21 days storage for both resin cements.

Materials are applied to enamel or dentin or both, and most also come into contact with oral fluids after placement. Some adverse effects have been reported following clinical use of the materials, although fortunately these are of low to moderate incidence. ${ }^{22}$ The cytotoxicity ranking of the most widely used monomers was BisGMA >UDMA>TEGDMA $>$ HEMA $>$ MMA. It was further shown that the cytotoxicity of these substances was related to their lipophilicity. ${ }^{35,36}$ In the present study, the highest mean concentrations of residual TEGDMA from resin cements (Variolink II, Rely X ARC, Rely X Unicem, and Resilute ) were $203.8 \mu \mathrm{M}, 219.9 \mu \mathrm{M}, 190.1 \mu \mathrm{M}$, and $282.5 \mu \mathrm{M}$, respectively. According to other studies ${ }^{37-40}$ on the cytotoxic effects of residual monomers, these concentrations of residual monomers in the current study may cause adverse reactions in human cells.

Elution of residual monomers from resin materials involves degree of their polymerization, properties of resin composition, and chemistry of organic solvents in vitro. ${ }^{23}$ Several factors affect the elution process of residual monomers in vivo. One of the factors involves dentists applying resin materials. From this perspective, the application and polymerization process of resin materials according to manufacturers' instructions gains importance. In addition, seating of restorations and the thickness of resin materials between tooth and restoration are important due to contact between the surface of the resin material and oral fluids. The second factor involves patients and their oral environments. Oral fluids of humans can different according to their chemical composition, enzymes and oral stresses. The third factor involves the steps of the application process of resin materi- 
als. With increasing steps, the operational sensitivity may be influenced so that the polymerization of resin materials might be insufficient. Monomer conversion values of dentin bonding agents applied and light-cured alone were not determined in this study. Because the chemistry of the analysed interface changed when the resin was applied and diffused into the uncured bonding agent, direct comparison of conversion values between the lightcured bonding agent alone and that of the mixture of the bonding agent and cement cannot be made. Thus, the significance of these differences is not known. ${ }^{41}$ For this reason, the experimental setup did not consider the effects of an in vivo situation, and elution of the residual monomers measured cannot be directly applied to the elution of residual monomers in vivo. Therefore, in vivo studies are needed for the evaluation of residual monomers and their effects.

\section{CONCLUSION}

1. Residual monomer (TEGDMA) was eluted from resin cement in all time interval.

2. The cumulative amount of eluted TEGDMA was increased as a function of time.

3. The highest cumulative amount of TEGDMA was detected in 21 days.

4. While the highest cumulative amount of TEGDMA was eluted from Resilute, Rely X Unicem showed the lowest TEGDMA elution.

5. The highest amount of eluted TEGDMA concentration detected was viewed as critical for toxic reactions in human cell.

\section{REFERENCES}

1. Sideridou ID, Achilias DS. Elution Study of Unreacted BisGMA, TEGDMA, UDMA, and Bis-EMA from Light-Cured Dental Resins and Resin Composites Using HPLC. J Biomed Mater Res B Appl Biomater 2005;74:617-626.

2. Burke FJ. The effect of variations in bonding procedure on fracture resistance of dentin-bonded all-ceramic crowns. Quintessence Int 1995;26:293-300.

3. Christensen JC. Porcelain-fused-to-metal vs. nonmetal crowns. J Am Dent Assoc 1995;130:409-411.

4. Stewart $P G$, Jain $P$, Hodges J. Shear bond strength of resin cements to both ceramic and dentin. J Prosthet Dent 2002;88:277-284

5. Banks RG Conservative posterior ceramic restorations: a literature review. J Prosthet Dent 1990;63:619-626.
6. Lehner C, Studer S, Brodbeck U, Schärer P. Six-year clinical results of leucite-reinforced glass ceramic inlays and onlays. Acta Med Dent Helv 1998;3:137-146.

7. Stanislawski L, Lefeuvre M, Bourd K, Soheili-Majd E, Goldberg M. TEGDMA-induced toxicity in human fibroblasts is associated with early and drastic glutathione depletion with subsequent production of oxygen reactive species. $J$ Biomed Mater Res 2003;66:476-482.

8. Swhweikl H, Schmalz G. Triethylene glycol dimethacrylate induces large deletions in the HPRT gene of V79 cells. $\mathrm{Mu}$ tat Res 1999;438:71-78.

9. Hansel C, Leyhausen G, Mai UEH, Geurtsen W. Effects of varius resin composite (colmonomers and extracts on two caries-associated micro-organisms in vitro. J Dent Res 1998;77:60-67.

10. Munksgaard EC, Peutzfeldt A, Asmussen E. Elution of TEGDMA and BisGMA from a resin and a resin composite cured with halogen or plasma light. Eur J Oral Sci 2000;108:34145.

11. Moharamzadeh K, Van Noort R, Brook IM, Scutt AM. HPLC analysis of components released from dental composites with different resin compositions using different extraction media. J Mater Sci: Mater Med 2007;18:133-137.

12. Bagis $Y H$, Rueggeberg FA. The effect of post-cure heating on residual, unreacted monomer in a commercial resin composite. Dent Mater 2000;16:244-247.

13. Hamid A, Hume WR. A study of component release from resin pit and fissure sealants in vitro. Dent Mater 1997; 13:98-102.

14. Lee S-Y, Greener EH, Menis DL. Detection of leached moieties from dental composites in fluids simulating food and saliva. Dent Mater 1995;11:348-353.

15. Lee S-Y, Huang H-M, Lin C-Y, Shih Y-H. Leached components from dental composites in oral simulating fluids and the resultant composite strengths. J Oral Rehabil $1998 ; 25: 575-588$

16. Michelsen VB, Lygre $H$, Skalevik R, Tveit AB, Solheim E. Identification of organic eluates from four polymer-based Dental filling materials. Eur J Oral Sci 2003;111:263-271.

17. Sieber C. In light of nature. Quintessenz Zahntech 1993;17:1301-1314.

18. Spahl W, Budzikiewicz H, Geurtsen W. Determination of leachable components from four commercial dental composites by gas and liquid chromatography/mass spectrometry. J Dent 1998;26:137-145.

19. Tanaka K, Taira M, Shintani H, Wakasa K, Yamaki M. Residual monomers (TEGDMA and Bis-GMA) of a set visiblelight-cured dental composite resin when immersed in water. J Oral Rehabil 1991;18:353-362. 
20. Geurtsen W. Substances released from Dental resin composites and glass ionomer cements. Eur J Oral Sci 1998; 106:687-695.

21. Castelnuovo J, Tjan AH, Phillips K, Nicholls JI, Kois JC. Fracture load and mode of failure of ceramic veneers with different preparations. J Prosthet Dent 2000;83:171-180

22. Hume WR, Gerzina TM. Bioavailability of components of resin-based materials which are applied to teeth. Crit Rev Oral Biol Med 1996;7:172-179.

23. Ferracane JL. Elution of leachable components from composites. J Oral Rehabil 1994;21:441-452.

24. Usumez S,Buyukyilmaz T,Karaman Al and Gunduz B. Degree of conversion of two lingual retainer adhesives cured with different light sources. Eur J Orthod 2005;27:173-179.

25. Asmussen E, Peutzfeldt A. Influence of light-exposure duration of the amount of leachable monomers from light-activated relines materials. J Prosthet Dent 2002;751:83-187.

26. Gerzina TM, Hume WR. Effect of dentine thickness on diffusion of resin monomers in vitro. J Oral Rehabil 1997;24:2025.

27. Komurcuoglu E, Olmez S, Vural N. Evaluation of residual monomer elimination methods in three different fissure sealants in vitro. J Oral Rehabil 2005;32:116-121.

28. Rueggeberg FA, Craig RR. Correlation of parameters used to estimate monomer conversion in a light-cured composite. J Dent Res 1998;67:932-937.

29. Pearson GJ, Longman CM. Water sorption and solubility of resin based materials following inadequate polymerization by a visible-light curing system. J Oral Rehabil 1989;16:5761.

30. Eliades T, Eliades G, Brantley WA, Johnston WM. Residual monomer leaching from chemically cured and visible light cured orthodontic adhesives. Am J Orthodont Dentofac Orthoped 1995; 108:316-321.

31. Chung $\mathrm{KH}$. The relationship between composition and properties of posterior resin composites. J Dent Res 1990;69:852-856.

32. Braga RR, Ballester RY,Carrilho MR. Pilot study on the early shear strength of porcelain-dentin bonding using dualcure cements. J Prosthet Dent 1999;81:285-289

33. Krishnan VK, Manjusha K, Yamuna V. Effect of diluent upon the properties of a visible-light-cured dental composite. $J$ Mater Sci Mater Med 1997;8:703-706.

34. Kawahara T, Nomurab Y, Tanakaa N, Teshimac W, Okazakib M, Shintania H. Leachability of plasticizer and residual monomer from commercial temporary restorative resins. $J$ Dent 2004;32:277-283.

35. Altintas $\mathrm{SH}$, Usumez A. Evaluation of monomer leaching from a dual cured resin cement. J Biomed Mater Res B Appl Biomater 2008;86:523-529
36. Yoshii E. Cytotoxic effects of acrylates and methacrylates: Relationships of monomer structures and cytotoxicity. $J$ Biomed Mater Res 1997;37:517-524.

37. Geurtsen W, Lehmann F, Spahl W, Leyhausen G Cytotoxicity of 35 dental resin composite monomers/additives in permanent 3T3 and three human primary fibroblast cultures. J Biomed Mater Res 1998;41:474-480.

38. Hanks CT, Strawn SE, Wataha JC, Craig RG. Cytotoxic effects of resin components on cultured mammalian fibroblasts. J Dent Res 1991;70:1450-1455

39. Ratanasathien S, Wataha JC, Hanks CT, Dennison JB. Cytotoxic interactive effects of dentin bonding components on mouse fibroblasts. J Dent Res 1995;74:1602-606.

40. Schwengberg S, Bohlen H, Kleinsasser N, Kehec K, Seiss M, Walther UI, Hickel R, Reichl RX. In vitro embryotoxicity assessment with dental restorative materials. $J$ Dent 2005;33:49-55

41. Arrais CA, Rueggeberg FA, Waller JL, de Goes MF, Giannini M. Effect of curing mode on the polymerization characteristics of dual-cured resin cement systems. J Dent $2008 ; 36: 418-426$. 